\title{
Brain delivery of vasoactive intestinal peptide (VIP) following nasal administration to rats
}

\author{
Christine Dufes ${ }^{\mathrm{a}, \mathrm{b}}$, Jean-Christophe Olivier ${ }^{\mathrm{a}, *}$, Frédéric Gaillard $^{\mathrm{c}}$, \\ Afsaneh Gaillard ${ }^{\mathrm{c}}$, William Couet ${ }^{\mathrm{a}}$, Jean-Marc Muller ${ }^{\mathrm{b}}$ \\ ${ }^{a}$ Equipe émergente Médicaments Anti-infectieux et Barrière Hématoencéphalique, Laboratoire de Pharmacie Galénique et Biopharmacie, \\ Faculté de Médecine et de Pharmacie, 34 rue du Jardin des Plantes, BP199, 86005 Poitiers Cedex, France \\ ${ }^{\mathrm{b}}$ Laboratoire de Biologie des Interactions Cellulaires, CNRS UMR 6558, Faculté des Sciences, 40 avenue du Recteur Pineau, \\ 86022 Poitiers Cedex, France \\ ${ }^{\mathrm{c}}$ Laboratoire du Développement Cortical, CNRS UMR 6558, Faculté des Sciences, 40 avenue du Recteur Pineau, \\ 86022 Poitiers Cedex, France
}

Received 24 June 2002; received in revised form 10 January 2003; accepted 14 January 2003

\begin{abstract}
The aim of this work was to study in rats the nasal route for the brain delivery of the vasoactive intestinal peptide (VIP) neuropeptide. After evaluating VIP stability in solutions obtained from nasal washes, the effect of formulation parameters ( $\mathrm{pH} 4-9,0-1 \%(\mathrm{w} / \mathrm{v})$ lauroylcarnitine (LC), hypo- or isoosmolality) on the brain uptake of intranasally administered VIP $\left(10^{-8} \mathrm{M}\right){ }^{/ 25} \mathrm{I}$-VIP $(300,000 \mathrm{cpm} / \mathrm{ml})$ was studied, using an in situ perfusion technique. Brain radioactivity distribution was assessed by quantitative autoradiographic analysis. Results were compared to intravenously administered VIP. With a hypotonic formulation at $\mathrm{pH} 4$ containing $0.1 \%$ LC and $1 \%$ bovine serum albumin, VIP stability was satisfactory and loss by adsorption was minimal. Using this formulation, around $0.11 \%$ of initial radioactivity was found in the brain after 30 min perfusion and was located in the olfactory bulbs, the midbrain and the cerebellum. HPLC analysis of brain and blood extracts demonstrated the presence of intact VIP in brain and its complete degradation in the blood compartment. By intravenous administration, no intact VIP was found either in brain or in blood. In conclusion, intact VIP could be delivered successfully to the brain using the intranasal route for administration.
\end{abstract}

(C) 2003 Elsevier Science B.V. All rights reserved.

Keywords: VIP; Vasoactive intestinal peptide; Nasal administration; Neuropeptide; Brain delivery; Lauroylcarnitine

\section{Introduction}

The brain delivery of large hydrophilic drug molecules (peptides, proteins) is severely hindered by the presence of the blood-brain barrier (BBB) which

\footnotetext{
* Corresponding author. Tel.: +33-5-49-45-45-92; fax: $+33-5-49-45-43-78$.

E-mail address: jean.christophe.olivier@univ-poitiers.fr (J.-C. Olivier).
}

strictly controls the access of solutes to the brain (Begley, 1996). Several strategies, such as drug lipidization, conjugation to ligands or incorporation in BBB-targeting liposomes have been proposed to cross the BBB (Pardridge, 1998). Besides, the intranasal route offers a much simpler approach for brain drug delivery (Illum, 2000). The olfactory receptor cells are in contact with both the nasal cavity and the central nervous system (CNS) (Uraih and Maronpot, 1990) and this neuronal connection constitutes a 
direct pathway to the brain, the drugs reaching the brain parenchyma mainly by a paracellular route (Mathison et al., 1998; Illum, 2000). By intranasal administration, drugs not only circumvent the BBB, but they also avoid the hepatic first-pass effect and/or degradation in the blood compartment, a particularly important issue in the case of peptide drugs. Intranasally administered proteins or peptides, e.g. wheat germ agglutinin-horseradish peroxidase (Shipley, 1985), nerve growth factor (NGF) (Frey et al., 1997), and insulin (Gizurarson et al., 1997), were demonstrated to reach the CNS. A pharmacological response was evidenced after intranasal administration of a lipophilic vasoactive intestinal peptide (VIP) analogue unable to cross the BBB (Gozes et al., 1996).

VIP is a 28-amino acid neuropeptide of the glucagon-secretin family (Mutt and Said, 1970) with a widespread distribution in both the central and peripheral nervous system (Fahrenkrug, 1979). It exerts diverse peripheral biological functions, such as anti-inflammatory and immunomodulatory effects, smooth muscle relaxation, regulation of cell growth and differentiation and participates in the function and in the development of neural tissue (Muller et al., 1995). It also plays an important role in the cerebral metabolism (Magistretti et al., 1981) and is involved in cerebral carcinogenesis (Lelièvre et al., 1998). VIP could have interesting applications in the treatment of various neurological disorders, like Alzheimer's disease, and a lipophilic VIP analogue was proposed for such a therapeutic application (Gozes et al., 1996). However, like most endogenic peptides, its potential therapeutic applications are limited by its failure to cross the BBB (McCulloch and Edvinsson, 1980) and its rapid elimination after intravenous administration. Its half-life in vivo in blood was determined to be less than $1 \mathrm{~min}$ in rat (Hassan et al., 1994) and approximately $1 \mathrm{~min}$ in man (Domschke et al., 1978). In order to solve this problem, liposomal formulations for intravenous use have been proposed to protect VIP from degradation (Gao et al., 1994; Gololobov et al., 1998; Önyüksel et al., 1999). As liposomes were unable to cross the BBB, the sole pharmacological effect obtained was a peripheral vasodilation (Gao et al., 1994). For brain delivery, a VIP analogue was conjugated to the OX26 monoclonal murine antibody directed against the rat transferrin receptor (Bickel et al., 1993). This conjugation permitted a significant brain uptake of the analogue administered intravenously in rats, associated with a $65 \%$ increase in cerebral blood flow. For the treatment of neurological disorders, however, systemic administration of VIP entrapped in liposomes or in the form of long-lasting analogue should be avoided, in respect to the multiple biological effects of VIP on peripheral tissues which could lead to major adverse effects (Verner-Morrison Syndrome) (Domschke et al., 1978). VIP is therefore an interesting model to evaluate the potential advantages of the intranasal over the intravenous route for brain delivery of peptides. One could expect that after intranasal administration VIP may reach the brain tissue in an intact form via the direct nose-to-brain pathway, whereas the fraction of VIP that may reach the blood compartment would be considerably reduced, thus avoiding potential peripheral adverse effects.

The aim of this study was to investigate the brain uptake of VIP after nasal administration, including the effect of some formulation parameters on this uptake $(\mathrm{pH}$, osmolality and the presence of lauroylcarnitine (LC) as a permeation enhancer).

\section{Experimental}

\subsection{Chemicals}

Human VIP (pI 9.82, $M_{\mathrm{w}}$ 3326.82, calculated using the ExPASy Proteomics Tools from the www.expasy.ch/tools website) was obtained from Neosystem (France). ${ }^{125} \mathrm{I}-\mathrm{Na}(2200 \mathrm{Ci} / \mathrm{mmol})$ was provided by NEN DuPont (France). Chloramine T, D,L-lauroylcarnitine chloride, bovine serum albumin (BSA), sodium metabisulfite, trifluoroacetic acid (TFA) were purchased from Sigma (France).

\subsection{Animals}

The animal experiments adhered to the Principles of Laboratory Animal Care (NIH Publication \#86-23, revised 1985). Male Sprague-Dawley rats (250-300 g) obtained from Déprés Breeding Laboratories (St. Doulchard, France) were housed in the animal breeding facilities of the laboratory (Authorization No. 0028) for 4-6 days before experiments. They were maintained in a light- (12-h light-dark cycle) and temperature-controlled environment with 
free access to water and food. Food was withdrawn $24 \mathrm{~h}$ before experiments.

\subsection{VIP radiolabelling and purification}

VIP was radioiodinated on $\mathrm{Tyr}^{10}$ using the chloramine $\mathrm{T}$ method as previously described (Martin et al., 1986). Briefly, the reaction was initiated by addition of $25 \mu \mathrm{l}$ of a $3 \mathrm{mg} / \mathrm{ml}$ chloramine $\mathrm{T}$ solution (prepared in a $0.2 \mathrm{M}$ sodium phosphate buffer $(\mathrm{pH}$ 7.6)) to $15 \mu \mathrm{l}$ of a $10^{-4} \mathrm{M}(5 \mu \mathrm{g})$ aqueous solution of VIP mixed with $5 \mu$ l of ${ }^{125} \mathrm{I}-\mathrm{Na}$ solution (around $0.45 \mathrm{mCi}$ ). After $1 \mathrm{~min}$, the reaction was stopped with $25 \mu \mathrm{l}$ of a $2 \mathrm{mg} / \mathrm{ml}$ sodium metabisulfite prepared in the same buffer. The radioiodination mix was then passed on a $\mathrm{C}_{18}$ Sep-Pak column (Waters Associates) using $10 \mathrm{ml}$ of a $0.1 \%$ trifluoroacetic acid (TFA) aqueous solution as eluent in order to discard free radioiodine. ${ }^{125}$ I-VIP was then recovered using $2.5 \mathrm{ml}$ of $85: 15$ acetonitrile:0.1\% TFA in water as eluent. It was further purified by reversed-phase HPLC. The fractions containing the monoiodinated form of $\left.{ }^{125} \mathrm{I}-\mathrm{VIP}\left(\mathrm{Tyr}^{10}{ }^{1}{ }^{125} \mathrm{I}\right) \mathrm{VIP}\right)$ were dried under nitrogen and stored at $-20^{\circ} \mathrm{C}$.

\subsection{Animal experiments}

\subsubsection{Intranasal administration procedure}

The intranasal administration procedure was based on the in situ nasal multipass perfusion method of Hirai et al. (1981). Overnight fasted male SpragueDawley rats $(250-300 \mathrm{~g})$ were anesthetized by intraperitoneal injection of $20 \%(\mathrm{w} / \mathrm{v})$ ethylurethane $(1 \mathrm{~g} / \mathrm{kg}$ body weight), which permitted an effective anesthesia all over the experiment. After incision of the neck of the rat laying on its back under a heating lamp, the trachea was cannulated with a polyethylene tube (i.d. $1.19 \mathrm{~mm}$, e.d. $1.70 \mathrm{~mm}$, no. 8, Polylabo, France) to aid breathing. Another polyethylene tube (i.d. $0.86 \mathrm{~mm}$, e.d. $1.52 \mathrm{~mm}$, no. 6) was inserted through the esophagus toward the posterior part of the nasal cavity. It was connected to a reservoir of solution (buffers in the case of preliminary VIP stability experiments or VIP formulations in the case of brain uptake experiments) at $37^{\circ} \mathrm{C}$ in a water-bath. The nasopalatine tract was sealed using cyanoacrylate glue to prevent the drainage of solution from the nasal into the oral cavity. By means of a peristaltic pump (Minipuls
II, Gilson) the solution ( $1.5 \mathrm{ml})$ was circulated for 30 min (except when stated differently) from the reservoir through the nasal cavity and out of the nostrils back into the reservoir at a flow rate of $2 \mathrm{ml} / \mathrm{min}$.

\subsubsection{Stability of VIP in nasal wash solutions}

VIP stability was evaluated in nasal wash solutions using a method adapted from Aungst and Phang (1995). To prepare the nasal wash solutions, three hypotonic $(20 \mathrm{mOsm} / \mathrm{kg})$ buffered solutions $(10 \mathrm{mM}$ citrate $(\mathrm{pH} 4)$ or $10 \mathrm{mM}$ phosphate buffer $(\mathrm{pH} 7$ or 9)) were circulated for $30 \mathrm{~min}$ as described above to collect mucosal secretions. To $330 \mu \mathrm{l}$ of these solutions supplemented with $1 \%(\mathrm{w} / \mathrm{v})$ BSA were added VIP $\left(10^{-8} \mathrm{M}\right.$ final concentration $)$ and ${ }^{125} \mathrm{I}$-VIP $\left(300,000 \mathrm{cpm} / \mathrm{ml}\right.$ final concentration, $\left.7.5 \times 10^{-11} \mathrm{M}\right)$ and the mix $(450 \mu \mathrm{l})$ was incubated at $37^{\circ} \mathrm{C}$ for $30 \mathrm{~min}$. The effect of $0.1 \% \mathrm{LC}(\mathrm{w} / \mathrm{v})$ on VIP stability was also evaluated. To check for peptide adsorption onto polyethylene containers, VIP was incubated in

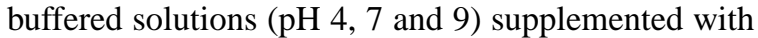
$1 \%(w / v)$ BSA. All the samples were analyzed by HPLC and the collected fractions that contained intact VIP were counted using a Cobra II Auto-Gamma Counting System (Packard, USA). Concentrations were calculated using a standard $10^{-8} \mathrm{M}$ VIP solution (containing 300,000 cpm/ $/ \mathrm{ml}^{125} \mathrm{I}-\mathrm{VIP}$ ) prepared at $\mathrm{pH}$ 4 with $1 \%(\mathrm{w} / \mathrm{v}) \mathrm{BSA}$ just prior to analysis. A second series of VIP stability experiments was also carried out by checking the ability of $10^{-8} \mathrm{M}$ unlabelled VIP incubated in nasal wash solutions to inhibit ${ }^{125} \mathrm{I}$-VIP binding in chicken liver membrane (see Section 2.6).

\subsubsection{Evaluation of brain uptake after intranasal perfusions}

Perfusing solutions $(1.5 \mathrm{ml})$ contained $10^{-8} \mathrm{M}$ VIP, ${ }^{125} \mathrm{I}-\mathrm{VIP}(300,000 \mathrm{cpm} / \mathrm{ml})$ and $1 \%(\mathrm{w} / \mathrm{v}) \mathrm{BSA}$ and were prepared (i) in $10 \mathrm{mM}$ citrate $(\mathrm{pH} 4)$ or $10 \mathrm{mM}$ phosphate buffer ( $\mathrm{pH} 7$ or 9), (ii) without or with absorption enhancer (D,L-lauroylcarnitine chloride, $0.1 \%$ or $1 \% \mathrm{w} / \mathrm{v})$, (iii) in hypotonic $(20 \mathrm{mOsm} / \mathrm{kg})$ solution or in solution made isotonic $(300 \mathrm{mOsm} / \mathrm{kg})$ by addition of sodium chloride. In order to minimize loss by adsorption, tubing and containers used for nasal perfusion were previously pre-conditioned by circulating similar solutions for $30 \mathrm{~min}$ before performing in vivo experiments: conditioning was confirmed by determining VIP concentration by $\gamma$-counting. At the end of 
the intranasal perfusion, a blood sample was collected by intracardiac puncture. A $300 \mathrm{ml}$ volume of saline $(0.9 \% \mathrm{w} / \mathrm{v}$ sodium chloride) was then infused into the aorta to remove blood from brain vessels. The skull was opened and the brain collected and weighed. The radioactivity was determined in brain and in blood by $\gamma$-counting. Three rats were used per condition.

\subsubsection{Qualitative analysis of brain or blood samples by HPLC: comparison between intranasal and intravenous administrations of VIP}

A qualitative analysis of brain and blood samples was carried out by HPLC to check for the VIP integrity after intranasal or intravenous routes. For intranasal administration, the in situ nasal perfusion was carried out for $30 \mathrm{~min}$ as described above, with a solution of VIP $\left(10^{-8} \mathrm{M}\right)$ and ${ }^{125} \mathrm{I}-\mathrm{VIP}\left(14 \times 10^{6} \mathrm{cpm} / \mathrm{ml}\right)$ prepared in $0.01 \mathrm{M}$ citrate buffer $(\mathrm{pH} 4)$ supplemented with $1 \%(\mathrm{w} / \mathrm{v})$ BSA and with LC $(0.1 \%$ $\mathrm{w} / \mathrm{v})$. For the intravenous route, a solution of VIP $\left(3.6 \times 10^{-10} \mathrm{M}\right)$ and ${ }^{125} \mathrm{I}-\mathrm{VIP}(500,000 \mathrm{cpm} / \mathrm{ml})$ in saline supplemented with $1 \%(\mathrm{w} / \mathrm{v})$ BSA was infused for $30 \mathrm{~min}$ at a $4 \mathrm{ml} / \mathrm{h}$ flow rate, via an indwelling jugular vein polyethylene cannula (i.d. $0.58 \mathrm{~mm}$, o.d. $0.96 \mathrm{~mm}$, Portex, France), with a PX 20B pump Ulis (France). Brains, washed as described above, and blood samples $(600 \mu \mathrm{l})$ were homogenized on ice with two volumes of $10 \mathrm{mM}$ Tris buffer ( $\mathrm{pH} \mathrm{8)}$ containing protease inhibitors $(1 \mathrm{mg} / \mathrm{ml}$ bacitracin, $1 \mathrm{mM}$ phenylmethylsulfonylfluoride, $0.2 \mathrm{mM}$ antipain and $2 \mathrm{mM}$ orthophenanthroline) using a Potter tissue homogenizer, and were centrifuged at $4{ }^{\circ} \mathrm{C}(1000 \times g$ for $10 \mathrm{~min}$ ). Supernatants were collected and stored on ice. The same extraction procedure was applied two more times to the pellets. Finally, the three supernatants collected for each sample were pooled and ultracentrifuged at $100,000 \times g$ for $30 \mathrm{~min}$ at $4{ }^{\circ} \mathrm{C}$ using an Optima LE-80K ultracentrifuge (Beckman, France) to spin down any remaining tissue debris. The clear supernatant layers were collected and dried under vacuum using a Speed-Vac (Heto Maxi Dry Lyo FD1.0). Extracts were dissolved in $200 \mu 1$ mobile phase prior to HPLC analysis.

\subsubsection{Brain distribution study after intranasal and intravenous VIP administrations}

Brain radioactivity distribution after intranasal administration of ${ }^{125}$ I-VIP was studied by quanti- tative autoradiographic analysis. A solution of VIP $\left(10^{-8} \mathrm{M}\right)$ and ${ }^{125} \mathrm{I}-\mathrm{VIP}(300,000 \mathrm{cpm} / \mathrm{ml})$ at $\mathrm{pH} 4$ was perfused intranasally for $30 \mathrm{~min}$ as described above. After removing blood from brain vessels, brains were fixed by infusing into the aorta $800 \mathrm{ml}$ of a $4 \%$ (w/v) paraformaldehyde solution in saline. Brains were serially sectioned at $2 \mathrm{~mm}$ thickness. Sections were then placed in a light-tight exposure cassette containing a phosphor screen (Molecular Dynamics, Sunnyvale, CA) for 3 weeks. Radioactivity signals were detected by a Storm 820 imaging system (Molecular Dynamics) using the ImageQuant software, and densitometric image analysis was carried out using a Scion Image for Windows software (National Institutes of Health, USA). Since the section thickness caused poor anatomical details, fractional radioactivity per section was presented here. Knowing the total amount of radioactivity in the brain (determined by $\gamma$-counting) and the weight of each section, the data were expressed as cpm per gram brain. Experiments were triplicated and five quantifications were performed per experiment. For brain radioactivity distribution after intravenous route, a solution of VIP $\left(3.6 \times 10^{-10} \mathrm{M}\right)$ and ${ }^{125} \mathrm{I}-\mathrm{VIP}(10,700 \mathrm{cpm} / \mathrm{ml})$ in saline supplemented with $1 \%(\mathrm{w} / \mathrm{v})$ BSA was intravenously infused for $30 \mathrm{~min}$ as described above and radioactivity was directly determined by $\gamma$-counting in each brain section.

\subsection{Reversed-phase HPLC analysis of VIP}

VIP reversed-phase HPLC was carried out using a $5 \mu \mathrm{m}$ VYDAC $\mathrm{C}_{18}$ column (Interchrom, France) with $\gamma$-counting of ${ }^{125}$ I-VIP. A two-step linear gradient was used with $0.1 \%(\mathrm{v} / \mathrm{v})$ TFA in water as solvent $\mathrm{A}$ and 85:15 acetonitrile:0.1\% (v/v) TFA in water as solvent $\mathrm{B}$. The column was equilibrated with solvent $\mathrm{A}$ at a $1 \mathrm{ml} / \mathrm{min}$ flow-rate. Injection volume was $100 \mu \mathrm{l}$. At each run, solvent $B$ increased linearly from 0 to $35 \%$ in $2 \mathrm{~min}$, then up to $100 \%$ in further $15 \mathrm{~min}$, and was maintained at $100 \%$ for another $5 \mathrm{~min}$. Fractions of $1 \mathrm{ml}$ were collected and $\gamma$-counted. VIP eluted in fractions 9-13 (see Fig. 1B).

\subsection{Radioreceptor assay}

Binding studies were performed on chicken liver cell membranes as previously described (Meunier

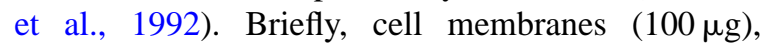


i.n. administration /

blood extract

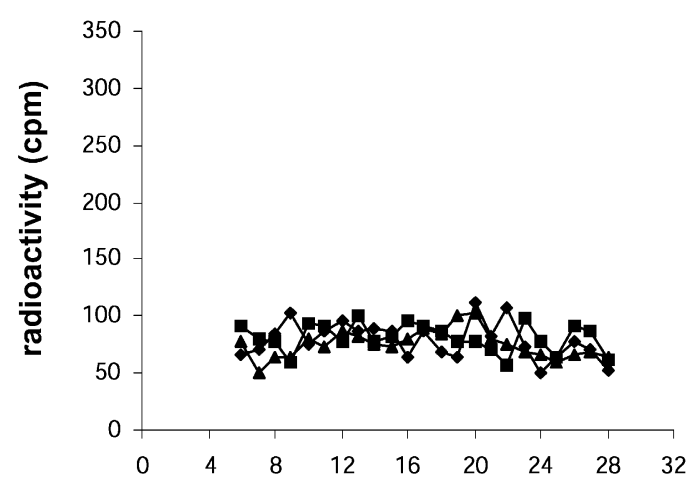

(A)

Fraction number

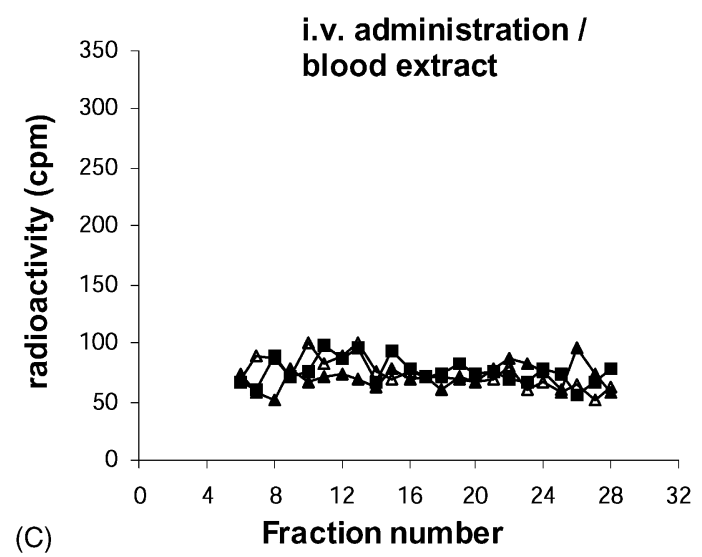

i.n. administration / brain extract
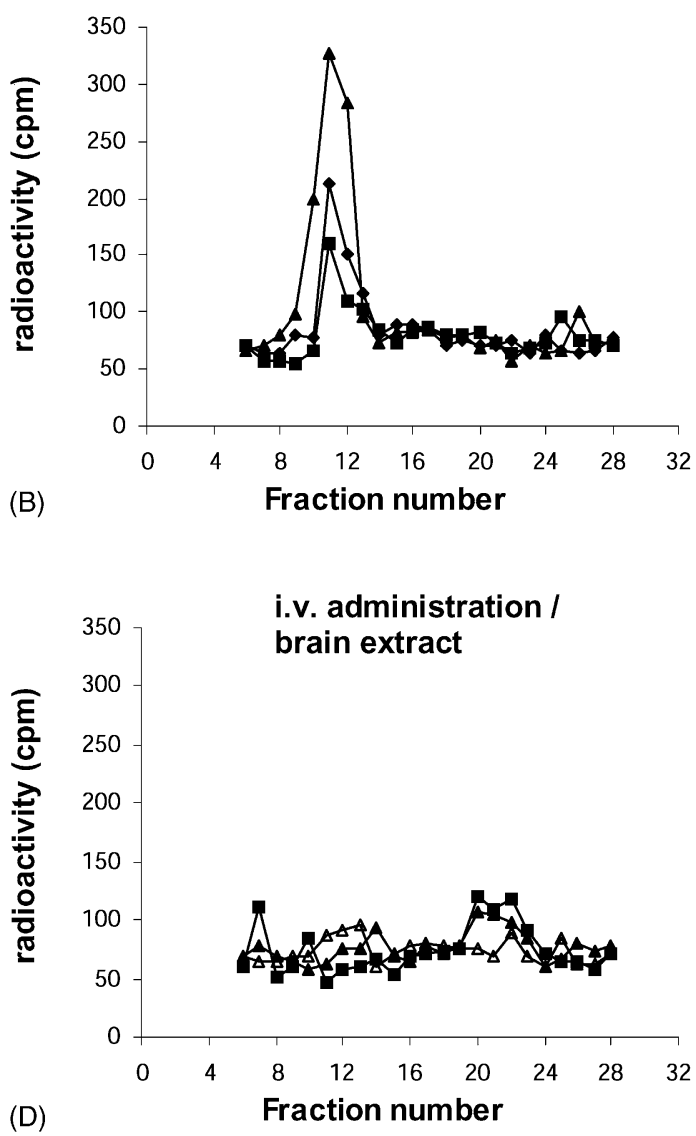

Fig. 1. Reversed-phase HPLC elution profiles of blood (A and C) or brain (B and D) extracts obtained after intranasal (i.n.) (A and B) or intravenous (i.v.) (C and D) administrations of VIP, using ${ }^{125} \mathrm{I}$-VIP as a tracer $(n=3) .{ }^{125} \mathrm{I}$-VIP was evaluated by $\gamma$-counting. Intact VIP eluted in fractions 9-13. For more details, see Section 2.

standard VIP solutions (or the VIP samples to be tested) and ${ }^{125} \mathrm{I}-\mathrm{VIP}(30,000 \mathrm{cpm})$ were incubated at room temperature and for $1 \mathrm{~h}$ in Dulbecco's modified Eagle's medium containing $15 \mathrm{mM}$ HEPES ( $\mathrm{pH} 7.4$ ), $1 \%(\mathrm{w} / \mathrm{v})$ BSA, $0.1 \%(\mathrm{w} / \mathrm{v})$ bacitracin and $150 \mu \mathrm{M}$ phenylmethylsulfonylfluoride (final volume: $400 \mu \mathrm{l}$ ). After stopping the binding reaction by cooling on ice, cell membranes were rinsed on Whatman GF/C filters (Polylabo, France) with $8 \mathrm{ml}$ of $150 \mathrm{mM}$ Tris buffer $\mathrm{pH} 7.5$, containing $5 \mathrm{mM} \mathrm{MgCl} 2,0.1 \%(\mathrm{w} / \mathrm{v})$ casein and $0.5 \%(\mathrm{w} / \mathrm{v})$ polyethyleneimine. The ${ }^{125} \mathrm{I}-\mathrm{VIP}$ still bound to the membranes was $\gamma$-counted. The VIP samples to be tested were evaluated by their ability to inhibit the ${ }^{125} \mathrm{I}$-VIP binding, using a $10^{-7} \mathrm{M}$ unlabelled VIP as a $100 \%$-inhibition control solution.

\subsection{Statistical analysis}

In vivo results were expressed as means \pm S.E.M. and statistical significance was determined by the Student's $t$-test to compare two groups or by one-way analysis of variance (ANOVA) followed by the Bonferroni's multiple comparison test for more than two groups. Differences were considered as significant when $P<0.05$. All in vivo experiments were repeated three times $(n)$. 
Table 1

Stability of VIP at $37^{\circ} \mathrm{C}$ in buffers and in nasal wash solutions: effect of $\mathrm{pH}$ and lauroylcarnitine (LC)

\begin{tabular}{|c|c|c|c|}
\hline \multirow[t]{3}{*}{$\overline{\mathrm{pH}}$} & \multicolumn{3}{|c|}{ VIP concentration $(\mathrm{M})$ after incubation } \\
\hline & \multirow[t]{2}{*}{ Buffers } & \multicolumn{2}{|c|}{ Buffered nasal wash solution } \\
\hline & & Without LC & With $0.1 \%$ LC (w/v) \\
\hline 4 & $1.00 \times 10^{-8}$ & $0.88 \times 10^{-8}(88 \%)$ & $0.84 \times 10^{-8}(84 \%)$ \\
\hline 7 & $0.90 \times 10^{-8}$ & $0.69 \times 10^{-8}(77 \%)$ & $0.81 \times 10^{-8}(90 \%)$ \\
\hline 9 & $0.71 \times 10^{-8}$ & $0.59 \times 10^{-8}(83 \%)$ & $0.70 \times 10^{-8}(100 \%)$ \\
\hline
\end{tabular}

VIP: initial concentration: $10^{-8} \mathrm{M}$.

Incubation time: $30 \mathrm{~min}$.

VIP: concentrations were determined by HPLC using ${ }^{125} \mathrm{I}-\mathrm{VIP}$ as a tracer. Percentages within parentheses are calculated using VIP control solutions as references. All the solutions contained 1\% (w/v) BSA.

\section{Results}

\subsection{Stability of VIP in nasal wash solutions}

Stability studies of VIP in nasal wash solutions are presented in Table 1. Controls incubated in buffers showed no loss by adsorption onto the polyethylene containers at $\mathrm{pH} \mathrm{4,} \mathrm{but} \mathrm{noticeable} \mathrm{loss} \mathrm{at} \mathrm{pH} 7$ and 9 , despite the addition of BSA. In order to take into account the ( $\mathrm{pH}$-dependent) adsorption phenomenon in the calculation of VIP loss by mucosal metabolism, results of VIP stability in nasal wash solutions were also expressed as percentage of controls incubated in buffer only. In all the conditions tested, VIP loss (attributed to mucosal metabolism) was less than $23 \%$ over $30 \mathrm{~min}$ incubation, which was considered as satisfactory. By radioreceptor assay, the ${ }^{125} \mathrm{I}-\mathrm{VIP}$ displacement by VIP incubated with nasal wash solutions was similar to a $10^{-8} \mathrm{M}$ concentration of native VIP (data not shown), indicating that the recovered VIP identified by HPLC was also able to bind to receptors.

\subsection{In situ nasal perfusion experiments}

The brain radioactivity uptake following intranasal perfusions was dependent on the $\mathrm{pH}$ of the perfusing solution: the highest uptake was observed at $\mathrm{pH} 9$ (Table 2). Adding $0.1 \% \mathrm{LC}$ to the perfusing solutions increased significantly radioactivity levels in brain at $\mathrm{pH} 4$ or at $\mathrm{pH} 7$ (the highest uptake being at $\mathrm{pH} 4$ ), but not at $\mathrm{pH} 9$, resulting in similar radioactivity counts for the three $\mathrm{pH}$ values tested (Table 2). More parameters were investigated at $\mathrm{pH} 4$ (Table 3 ). Increasing the $\mathrm{LC}$ concentration to $1 \%$ or the intranasal perfusion time from 30 to $120 \mathrm{~min}$ did not alter brain uptake. The addition of sodium chloride to make the perfusing solution isoosmotic decreased the radioactivity levels in brain, in comparison with results obtained without this additive. As a general observation, the fraction of radioactivity recovered in brain was quite low compared to the amount administered: with the most efficient formulation (i.e. $\mathrm{pH} 4,0.1 \% \mathrm{LC}$ ) the brain radioactivity levels after $30 \mathrm{~min}$ intranasal perfusion represented only $0.11 \pm 0.02 \%$ of the total radioactivity perfused intranasally. In all the conditions tested, radioactivity could be detected in blood (data not shown), indicating a passage of VIP and/or of radioactive degradation products from the nasal cavity into the blood compartment.

Table 2

Effect of $\mathrm{pH}$ on VIP uptake estimated from brain radioactivity measurements after intranasal administration

\begin{tabular}{|c|c|c|c|}
\hline $\begin{array}{l}\text { Brain uptake } \\
(\mathrm{cpm} / \mathrm{g} \pm \text { S.E.M.) }\end{array}$ & $\mathrm{pH} 4$ & $\mathrm{pH} 7$ & pH 9 \\
\hline Without LC & $65 \pm 13^{\mathrm{a}}$ n.s. & $\begin{array}{c}68 \pm 20^{\mathrm{b}} \\
P< \\
P<0.05\end{array}$ & $\begin{array}{l}153 \pm 1 \\
.05\end{array}$ \\
\hline With LC $0.1 \%$ & $217 \pm 47^{\mathrm{a}}$ & $154 \pm 2^{\mathrm{b}}$ & $148 \pm 52$ \\
\hline
\end{tabular}

a,b Significantly different $(P<0.05)$.

Intranasal perfusion time: $30 \mathrm{~min}$.

Osmolality: $20 \mathrm{mOsm} / \mathrm{kg}$.

Solutions: $10^{-8} \mathrm{M}$ VIP/7.5 $\times 10^{-11} \mathrm{M}^{125} \mathrm{I}$-VIP solutions, $1 \%(\mathrm{~m} / \mathrm{v})$ BSA with or without $0.1 \%(\mathrm{~m} / \mathrm{v})$ lauroylcarnitine $(\mathrm{LC})$ as permeation enhancer.

Data represent the mean \pm S.E.M. of three experiments. 
Table 3

Effect of some formulation parameters on VIP uptake after intranasal administration

\begin{tabular}{lccc}
\hline Formulation parameters tested & \multicolumn{2}{c}{ Brain uptake (cpm/g \pm S.E.M.) } \\
\cline { 1 - 3 } Lauroylcarnitine concentration $(\% \mathrm{w} / \mathrm{v})$ & Osmolality $(\mathrm{mOsm} / \mathrm{kg})$ & Intranasal perfusion time $(\mathrm{min})$ & \\
\hline 0.1 & 20 & 30 & $217 \pm 47^{\mathrm{a}}$ \\
0.1 & 20 & 120 & $130 \pm 13^{\mathrm{b}}$ \\
0.1 & 300 & 30 & $44 \pm 4^{\mathrm{c}}$ \\
1.0 & 20 & 30 & $118 \pm 8^{\mathrm{d}}$ \\
\hline
\end{tabular}

Solution: $10^{-8} \mathrm{M}$ VIP/7.5 $\times 10^{-11} \mathrm{M}^{125} \mathrm{I}-\mathrm{VIP}, 1 \%(\mathrm{w} / \mathrm{v}) \mathrm{BSA}, \mathrm{pH} 4$.

Data represent the mean \pm S.E.M. of three experiments. The superscript letters $a, b$, and $d$ are not significantly different. The superscript letters a and $\mathrm{c}$ are significantly different $(P<0.01) ; n=3$.

\subsection{Qualitative analysis of brain or blood extracts following intranasal or intravenous administrations}

For both routes, radioactivity was detected in brains and in blood samples (data not shown). HPLC analysis of the blood extracts showed no peak corresponding to intact VIP (Fig. 1A and C), by either administration routes. Analysis performed on the brain extracts showed one peak corresponding to intact VIP, after intranasal perfusions (fractions 9-13, Fig. 1B), but not after intravenous infusions (Fig. 1D).

\subsubsection{Brain distribution after nasal or intravenous administration}

Brain radioactivity distribution after intranasal perfusion or intravenous infusion is presented on Fig. 2.

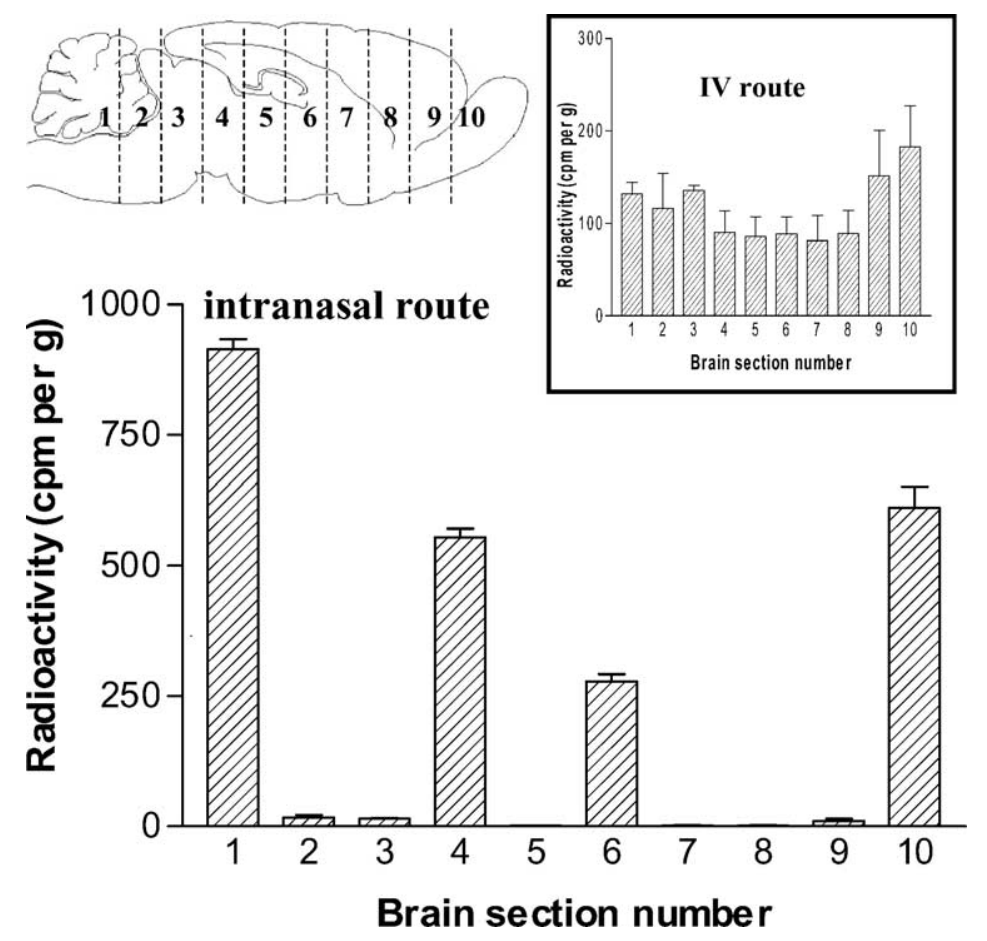

Fig. 2. Brain radioactivity distribution profiles after intranasal or intravenous (shown in the inset) administration of ${ }^{125}$ I-VIP. For intranasal perfusion, radioactivity was evaluated by quantitative autoradiographic analysis of 2-mm thick brain slices. For intravenous infusion, radioactivity was evaluated by $\gamma$-counting. The dotted lines on the rat brain representation (up left) denote the approximate spacing for the cutting of the brain sections. For more details, see Section 2. 
After intranasal perfusion, radioactivity was located in section 1 corresponding to the cerebellum, in sections 4 (approximately between $\beta-5$ and $\beta-6 \mathrm{~mm}$ ) and 6 (approximately between $\beta-2.1$ and $\beta-3.1 \mathrm{~mm}$ ) located in the midbrain, and in section 10 (approximately between $\beta+2.7$ and $\beta+1.7 \mathrm{~mm}$ ) corresponding to the olfactory bulbs and frontal cortex. After intravenous administration, radioactivity was homogeneously distributed in the whole brain.

\section{Discussion}

The VIP neuropeptide is unable to cross the BBB and undergoes a rapid degradation in blood in vivo. Therefore, the nasal route for administration was investigated for its brain delivery. Preliminary experiments were carried out to check for VIP loss by adsorption on polyethylene containers or by mucosal metabolism. In buffered solutions supplemented with $1 \%(\mathrm{w} / \mathrm{v})$ BSA, VIP $\left(10^{-8} \mathrm{M}\right)$ adsorbed readily on polyethylene containers at $\mathrm{pH} 9$ and at 7 , whereas no loss occurred at $\mathrm{pH} 4$ (Table 1). VIP is a polypeptide characterized by a high $\mathrm{pI}$ of 9.82 . As the adsorption of polypeptides is maximum at $\mathrm{pH}$ values close to the $\mathrm{pI}$ (Olivier et al., 1995), a pH above 7 should be avoided to minimize loss. After $30 \mathrm{~min}$ incubation in the presence of nasal wash solutions (with or without LC), the loss of VIP attributed to mucosal metabolism never exceeded $23 \%$ compared to control (Table 1). Radioreceptor assay confirmed the ability of the remaining VIP to interact with its receptors. VIP stability in the presence of nasal secretions was therefore considered as satisfactory. Mucosal metabolism should not be a barrier for VIP nasal absorption.

The in situ perfusion model of Hirai et al. (1981) was applied to study the influence of formulation parameters on the brain uptake of VIP administered intranasally. This model provides accurate information on basic parameters $(\mathrm{pH}$, osmolality, use of permeation enhancers) that govern nasal drug absorption (Olivier et al., 2001). In this model, drug concentration is generally determined in the perfusing solution, in order to quantify drug nasal absorption. In the case of VIP, due to its low nasal absorption, the resulting decrease in VIP concentration in the perfusing solution over 30 min was too low for an accurate evaluation of VIP absorption. Therefore, only brain radioactivity data were considered. In the absence of additive the brain uptake of intranasally administered VIP was $\mathrm{pH}$-dependent, with the highest uptake obtained at $\mathrm{pH}$ 9 (Table 2). The transport of small drug molecules to the cerebrospinal fluid from the nasal cavity was reported to be dependent on their lipophilicity (Sakane et al., 1991) and on their ionization state (Sakane et al., 1994). VIP is a lipophilic peptide (Noda et al., 1994), with a high pI (9.82). At a pH close to pI, VIP possesses a neutral global electric charge, which may facilitate its transmucosal absorption. The lower brain uptakes observed at $\mathrm{pH} 4$ or 7 were compensated by the addition of LC (Table 2). With $0.1 \%$ (w/v) LC in the formulation, the radioactivity levels in brain were similar for the three $\mathrm{pH}$ values tested and close to the maximum uptake obtained at $\mathrm{pH} 9$ without additive. At $\mathrm{pH} 4$, a higher concentration of LC (1\%) did not increase further the brain uptake (Table 3). LC, an endogenous amino acid-like surfactant, reportedly enhanced nasal absorption of polypeptides, such as azetirelin (Kagatani et al., 1998a) (tripeptide) and calcitonin (Kagatani et al., 1996) (32-amino acids), and of proteins, such as human growth hormone (Kagatani et al., 1998b) (191 amino acids), without inducing noticeable toxicity to the nasal mucosa. Its maximum effect was observed at acidic $\mathrm{pH}$ and for a concentration of $0.1 \%$ LC like in our experiments. The mechanism underlying the effect of long-chain acylcarnitines was studied on Caco- 2 cells by Hochman et al. (1994) who showed that palmitoylcarnitine micelles loosen epithelial tight junctions, thus enhancing drug absorption. The maximum effect observed at acidic $\mathrm{pH}$ is probably due to the fact that the micelles formed by the zwitterionic lauroylcarnitine (pK value of 4.85) at $\mathrm{pH} 4$ are cationic which may increase their interactions with the negatively charged nasal epithelium (Kagatani et al., 1996). Conversely, at $\mathrm{pH} 9$, the negatively charged zwitterion may have no or little interaction with the negatively charged mucosa, thus explaining their inefficiency at promoting VIP absorption. The addition of an osmotic agent (sodium chloride) to bring solutions to isoosmolality had a negative effect on VIP brain uptake (Table 3), probably because of a reduced transmucosal absorption, as previously reported with midazolam (Olivier et al., 2001) and with calcitonin (Dua et al., 1997). In contrast, hypotonic solutions cause cell swelling, which alters the epithelium paracellular permeability and helps for drug permeation 
through the mucosa (Pujara et al., 1995). Finally, a 120 min nasal perfusion time, in place of $30 \mathrm{~min}$, did not have any cumulative effect on the brain uptake. Even in optimal conditions of nasal administration, i.e. $\mathrm{pH} 4$ and $0.1 \%$ lauroylcarnitine, the radioactivity measured in brain was very low compared to the radioactivity levels applied intranasally: around $0.11 \%$ of the total radioactivity present in the perfusing solutions was detected in brain. This poor brain uptake was in accordance with previous similar works carried out with large polypeptides, such as insulin (Gizurarson et al., 1997) or NGF (Frey et al., 1995). For neuropeptides like VIP that are active at nanomolar, or even femtomolar, concentrations, intranasal administrations are likely to give pharmacological responses, as demonstrated for a VIP analogue (Gozes et al., 1996).

After intranasal administration of ${ }^{125}$ I-VIP, radioactivity was also detected in blood, indicating that a fraction of VIP (or VIP degradation product(s)) diffused from the nasal cavity into the blood compartment. As shown by HPLC analysis of blood extract (Fig. 1A), this fraction was not intact VIP. Hence, in blood, radioactivity corresponded to ${ }^{125} \mathrm{I}-\mathrm{VIP}$ degradation products only. The rapid and complete degradation of VIP in the blood compartment was in agreement with its very short VIP blood half-life (Hassan et al., 1994) in vivo and was confirmed by intravenous administration of VIP (Fig. 1C). In order to check that the radioactivity detected in brain after intranasal administration of ${ }^{125}$ I-VIP was actually emitted by ${ }^{125}$ I-VIP, and not by its blood-borne degradation products that could diffuse from the blood compartment into the parenchyma through the BBB or/and into BBB-lacking brain regions, like the circumventricular organs (Begley, 1996), brain samples were also qualitatively analyzed by HPLC. As shown in Fig. 1B, intranasally administered VIP (at least in part) reached brain as intact molecules. As expected, after intravenous infusion no intact VIP was found in brain (Fig. 1D). These experiments definitely demonstrated that the nasal route was effective to deliver to brain a peptide that is almost instantaneously degraded in the blood compartment when administered by intravenous route.

Quantitative autoradiographic analysis provided additional information on the brain radioactivity distribution following intranasal ${ }^{125} \mathrm{I}-\mathrm{VIP}$ perfusion: the radioactivity which corresponded, at least in part, to ${ }^{125}$ I-VIP was concentrated in specific brain sections (Fig. 2). This distribution profile was very different to the distribution profile obtained after intravenous ${ }^{125}$ I-VIP infusion: by IV, radioactivity, corresponding to blood-borne ${ }^{125} \mathrm{I}$-VIP degradation products, as shown by HPLC brain extract analysis (Fig. 1D), was homogeneously distributed in the whole brain (Fig. 2, inset). Interestingly, distribution after intranasal perfusion apparently corresponded to brain structures known to be very rich in VIP receptors (Besson, 1988): cerebellum and pontine reticular nuclei (section 1), the central grey, the geniculate, thalamic and amygdaloid nuclei (section 4), the thalamic, hypothalamic, amygdaloid nuclei, the primary olfactory cortex and the caudate putamen (section 6), the olfactory bulbs, the olfactory tubercle and the frontal cortex (section 10). It is unlikely that VIP reached all these brain areas following the same pathway. Drugs reach the olfactory bulbs by following the olfactory nerve pathway (i.e. within olfactory receptor cells) and/or the olfactory epithelial pathway (i.e. within the perineural space) (Illum, 2000). However, the way VIP reached specifically brain areas distant from the nasal cavity (sections 1, 4 and 6) remains to be determined. It is unlikely that VIP diffused through the parenchyma from the anterior to the posterior brain and specifically accumulated in brain structures rich in VIP receptors, as intraparenchymal diffusion is a very slow transfer process, very limited in extent (generally a few millimeters), therefore not compatible with the short duration of the intranasal infusions (30 $\mathrm{min})$ (Groothuis et al., 2000). Ceccatelli et al. (1991) suggested that physiological VIP was locally secreted by nerve fibers (e.g. of the local eminence) into the brain portal circulation for brain blood flow vascular regulation, thus implying that VIP could locally circulate in the blood compartment and interact with receptors of the brain vessels. A local redistribution of intranasally administered VIP from the nasal absorption site via the brain blood microcirculation to BBB-lacking brain areas, like the circumventricular organs (Begley, 1996), or to brain areas where VIP vascular receptors are particularly rich could therefore account for the observed brain distribution profile. The very short VIP blood half-life and the probably low amount of VIP involved in such pathway might explain why ${ }^{125}$ I-VIP was not detected in 
peripheral blood by HPLC. This hypothesis needs to be experimentally confirmed.

In conclusion, the hypotonic formulation of VIP at $\mathrm{pH} 4$ with $0.1 \%$ D,L-lauroylcarnitine and $1 \%$ BSA minimized VIP adsorption onto polyethylene tubes and permitted VIP brain delivery via the direct nose-to-brain pathway. Even if not completely satisfactory from a pharmaceutical view point due to the low brain uptake obtained, the nasal route for administration offers particularly interesting perspectives for the in vivo evaluation of the action of peptides on the CNS that cannot be administered intravenously, either because they cannot cross the BBB or because they are rapidly degraded in the blood compartment.

\section{References}

Aungst, B.J., Phang, S., 1995. Metabolism of a neurotensin (8-13) analog by intestinal and nasal enzymes, and approaches to stabilize this peptide at these absorption sites. Int. J. Pharm. $117,95-100$.

Begley, D.J., 1996. The blood-brain barrier: principles for targeting peptides and drugs to the central nervous system. J. Pharm. Pharmacol. 48, 136-146.

Besson, J., 1988. Distribution and pharmacology of vasoactive intestinal peptide receptors in the brain and pituitary. Ann. N.Y. Acad. Sci. 527, 204-219.

Bickel, U., Yoshikawa, T., Landaw, E.M., Faull, K.F., Pardridge, W.M., 1993. Pharmacologic effects in vivo in brain by vector-mediated peptide drug delivery. Proc. Natl. Acad. Sci. USA 90, 2618-2622.

Ceccatelli, S., Fahrenkrug, J., Villar, M.J., Hokfelt, T., 1991. Vasoactive intestinal peptide/peptide histidine isoleucine immunoreactive neuron systems in the basal hypothalamus of the rat with special reference to the portal vasculature: an immunohistochemical and in situ hybridization study. Neuroscience 43, 483-502.

Domschke, S., Domschke, W., Bloom, S.R., Mitznegg, P., Mitchell, S.J., Lux, G., Strunz, U., 1978. Vasoactive intestinal peptide in man: pharmacokinetics, metabolic and circulatory effects. Gut 19, 1049-1053.

Dua, R., Zia, H., Needham, T., 1997. The influence of tonicity and viscosity on the intranasal absorption of salmon calcitonin in rabbits. Int. J. Pharm. 147, 233-242.

Fahrenkrug, J., 1979. Vasoactive intestinal polypeptide: measurement, distribution and putative neurotransmitter function. Digestion 19, 149-169.

Frey, II, W.H., Liu, J., Thorne, R.G., Rahman, Y.E., 1995. Intranasal delivery of ${ }^{125}$ I-labeled nerve growth factor to the brain via the olfactory route. In: Iqbal, K., Mortimer, J.A., Winblad, B., Wisniewski, H.M. (Eds.), Research advances in Alzheimer's disease and related disorders. Wiley, New York, pp. 329-335.
Frey, W.H., Liu, J., Chen, X., Thorne, R.G., Fawcett, J.R., Ala, T.A., Rahman, Y.E., 1997. Delivery of ${ }^{125}$ I-NGF to the brain via the olfactory route. Drug Deliv. 4, 87-92.

Gao, X.P., Noda, Y., Rubinstein, I., Paul, S., 1994. Vasoactive intestinal peptide encapsulated in liposomes: effect on systemic arterial blood pressure. Life Sci. 54, PL247-PL252.

Gizurarson, S., Thorvaldsson, T., Sigurdsson, P., Gunnarsson, E., 1997. Selective delivery of insulin into the brain: intraolfactory absorption. Int. J. Pharm. 146, 135-141.

Gololobov, G., Noda, Y., Sherman, S., Rubinstein, I., BaranowskaKortylewicz, J., Paul, S., 1998. Stabilization of vasoactive intestinal peptide by lipids. J. Pharmacol. Exp. Ther. 285, 753-758.

Gozes, I., Bardea, A., Reshef, A., Zamostiano, R., Zhukovsky, S., Rubinraut, S., Fridkin, M., Brenneman, D.E., 1996. Neuroprotective strategy for Alzheimer disease: intranasal administration of a fatty neuropeptide. Proc. Natl. Acad. Sci. USA 93, 427-432.

Groothuis, D.R., Benalcazar, H., Allen, C.V., Wise, R.M., Dills, C., Dobrescu, C., Rothholz, V., Levy, R.M., 2000. Comparison of cytosine arabinoside delivery to rat brain by intravenous, intrathecal, intraventricular and intraparenchymal routes of administration. Brain Res. 856, 281-290.

Hassan, M., Refai, E., Andersson, M., Schnell, P.O., Jacobsson, H., 1994. In vivo dynamical distribution of ${ }^{131}$ I-VIP in the rat studied by gamma-camera. Nucl. Med. Biol. 21, 865-872.

Hirai, S., Yashiki, T., Matsuzawa, T., Mima, H., 1981. Absorption of drugs from the nasal mucosa of rat. Int. J. Pharm. 7, 317325.

Hochman, J.H., Fix, J.A., LeCluyse, E.L., 1994. In vitro and in vivo analysis of the mechanism of absorption enhancement by palmitoylcarnitine. J. Pharmacol. Exp. Ther. 269, 813-822.

Illum, L., 2000. Transport of drugs from the nasal cavity to the central nervous system. Eur. J. Pharm. Sci. 11, 1-18.

Kagatani, S., Shinoda, T., Fukui, M., Ohmura, T., Hasumi, S., Sonobe, T., 1996. Enhancement of nasal salmon calcitonin absorption by lauroylcarnitine chloride in rats. Pharm. Res. 13, 739-743.

Kagatani, S., Inaba, N., Fukui, M., Sonobe, T., 1998a. Nasal absorption kinetic behavior of azetirelin and its enhancement by acylcarnitines in rats. Pharm. Res. 15, 77-81.

Kagatani, S., Inaba, N., Fukui, M., Sonobe, T., 1998b. Nasal absorption kinetics of human growth hormone enhanced by acylcarnitines in rats. Int. J. Pharm. 169, 245-253.

Lelièvre, V., Pineau, N., Du, J., Wen, C.H., Nguyen, T., Janet, T., Muller, J.M., Waschek, J.A., 1998. Differential effects of peptide histidine isoleucine (PHI) and related peptides on stimulation and suppression of neuroblastoma cell proliferation. J. Biol. Chem. 273, 19685-19690.

Magistretti, P.J., Morrison, J.H., Shoemaker, W.J., Sapin, V., Bloom, F.E., 1981. Vasoactive intestinal polypeptide induces glycogenolysis in mouse cortical slices: a possible regulatory mechanism for the local control of energy metabolism. Proc. Natl. Acad. Sci. USA 78, 6535-6539.

Martin, J.L., Rose, K., Hughes, G.J., Magistretti, P.J., 1986. $\left[\right.$ Mono $\left[{ }^{125} \mathrm{I}\right]$ iodo-Tyr $\left.{ }^{10}-\mathrm{MetO}^{17}\right]$-vasoactive intestinal polypeptide. Preparation, characterization, and use for radioimmunoassay and receptor binding. J. Biol. Chem. 25, 53205327. 
Mathison, S., Nagilla, R., Kompella, U.B., 1998. Nasal route for direct delivery of solutes to the central nervous system: fact or fiction? J. Drug Target. 5, 415-441.

McCulloch, J., Edvinsson, L., 1980. Cerebral circulatory and metabolic effects of vasoactive intestinal polypeptide. Am. J. Physiol. 238, H449-H456.

Meunier, A.C., Carretier, M., El Battari, A., Luis, J., Karamanos, Y., Muller, J.M., 1992. Characterization of the human liver vasoactive intestinal peptide (VIP) receptor. Biomed. Res. 13, 157-161.

Muller, J.M., Lelievre, V., Becq-Giraudon, L., Meunier, A.C., 1995. VIP as a cell-growth and differentiation neuromodulator role in neurodevelopment. Mol. Neurobiol. 10, 115-134.

Mutt, V., Said, S.I., 1970. Polypeptide with broad biological activity: isolation from small intestine. Science 169, 12171218.

Noda, Y., Rodriguez-Sierra, J., Liu, J., Landers, D., Mori, A., Paul, S., 1994. Partitioning of vasoactive intestinal polypeptide into lipid bilayers. Biochim. Biophys. Acta 1191, 324330.

Olivier, J.C., Vauthier, C., Taverna, M., Ferrier, D., Couvreur, P., 1995. Preparation and characterization of biodegradable poly(isobutyl cyanoacrylate) nanoparticles with the surface modified by the adsorption of proteins. Colloids Surfaces B. Biointerfaces 4, 349-356.

Olivier, J.C., Djilani, M., Fahmy, S., Couet, W., 2001. In situ nasal absorption of midazolam in rats. Int. J. Pharm. 213, 187-192.
Önyüksel, H., Ikezaki, H., Patel, M., Gao, X.P., Rubinstein, I., 1999. A novel formulation of VIP in sterically stabilized micelles amplifies vasodilation in vivo. Pharm. Res. 16, 155160.

Pardridge, W.M., 1998. CNS drug design based on principles of blood-brain barrier transport. J. Neurochem. 70, 17811792.

Pujara, C.P., Shao, Z., Duncan, M.R., Mitra, A.K., 1995. Effects of formulation variables on nasal epithelial cell integrity: biochemical evaluation. Int. J. Pharm. 114, 197-203.

Sakane, T., Akizuki, M., Yamashita, S., Nadai, T., Hashida, M., Sezaki, H., 1991. The transport of drug to the cerebrospinal fluid directly from the nasal cavity: the relation to the lipophilicity of the drug. Chem. Pharm. Bull. 39, 24562458.

Sakane, T., Akizuki, M., Yamashita, S., Sezaki, H., Nadai, T., 1994. Direct drug transport from the rat nasal cavity to the cerebrospinal fluid: the relation to the dissociation of the drug. J. Pharm. Pharmacol. 46, 378-379.

Shipley, M.T., 1985. Transport of molecules from nose to brain: transneuronal anterograde and retrograde labeling in the rat olfactory system by wheat germ agglutinin-horseradish peroxidase applied to the nasal epithelium. Brain Res. Bull. $15,129-142$.

Uraih, L.C., Maronpot, R.R., 1990. Normal histology of the nasal cavity and application of special techniques. Environ. Health Perspect. 85, 187-208. 